\title{
\begin{tabular}{l|l} 
Mibraries & DSpace@MIT
\end{tabular}
}

\author{
MIT Open Access Articles
}

\section{Persuasive Backfiring: When Behavior Change Interventions Trigger Unintended Negative Outcomes}

The MIT Faculty has made this article openly available. Please share how this access benefits you. Your story matters.

Citation: Stibe, Agnis and Cugelman, Brian. “Persuasive Backfiring: When Behavior Change Interventions Trigger Unintended Negative Outcomes." Lecture Notes in Computer Science (2016): 65-77. (c) 2016 Springer International Publishing

As Published: http://dx.doi.org/10.1007/978-3-319-31510-2_6

Publisher: Springer International Publishing

Persistent URL: http://hdl.handle.net/1721.1/108479

Version: Author's final manuscript: final author's manuscript post peer review, without publisher's formatting or copy editing

Terms of Use: Article is made available in accordance with the publisher's policy and may be subject to US copyright law. Please refer to the publisher's site for terms of use. 


\title{
Persuasive Backfiring: When Behavior Change Interventions Trigger Unintended Outcomes
}

\author{
Agnis Stibe $^{1}$ and Brian Cugelman ${ }^{2,3}$ \\ ${ }^{1}$ MIT Media Lab, Cambridge, MA, USA \\ agnis@mit.edu \\ ${ }^{2}$ Statistical Cybermetrics Research Group, University of Wolverhampton, UK \\ ${ }^{3}$ AlterSpark, Toronto, ON, Canada \\ brian@alterspark.com
}

\begin{abstract}
Scholars and research teams focus their efforts on studying ways to improve the lives of individuals, which often brings tangible social benefits. However, there is scarce scientific knowledge available on negative outcomes of behavior change interventions, and possibly even fewer that report a special type of negative outcome, called a backfire. In this paper, we start a wider scientific discussion on intervention backfiring. We introduce a framework to help facilitate the debate of this topic. We provide tools to aid academics in the study of this realm and support practitioners to remain mindful of the potential risks when designing behavior change interventions. We describe taxonomy of persuasive backfiring and propose tools in the form of intention-outcome and likelihood-severity matrices to outline a roadmap for further research and application. We open transparent discussion on backfiring, with an attitude of looking out and coming up with strategies to reduce them whenever identified.
\end{abstract}

Keywords: persuasive technology, backfire, taxonomy, behavior change, intervention, intention-outcome matrix, likelihood-severity matrix

\section{Introduction}

Scholars have focused on the ways in which technology can produce positive outcomes, such as increasing users' physical activity (Marshall, Leslie, Bauman, Marcus, \& Owen, 2003), reducing binge drinking (Cunningham, Wild, Cordingley, Van Mierlo, \& Humphreys, 2009), quitting smoking (Lenert, Munoz, Perez, \& Bansod, 2004), or managing mood and anxiety disorders (Farvolden, Denisoff, Selby, Bagby, $\&$ Rudy, 2005). There are several systematic reviews and meta-analyses that focus on multiple positive outcomes, across a large number of independent studies (Cugelman, Thelwall, \& Dawes, 2011; Webb, Joseph, Yardley, \& Michie, 2010).

However, there are few papers that report negative outcomes, and possibly fewer that report a special type of negative outcome, called a backfire, which is what happens when an intervention triggers audiences to adopt the opposite target behavior, 
rendering the intervention partially responsible for causing the behavior it was designed to reduce.

Examples of backfiring interventions include drug use reduction programs that trigger drug use by making youth feel that everyone else is trying drugs except for them; traffic safety campaigns that use shame which results in denial and possible increased bad behavior by those who should feel shame; binge drinking screeners that trigger some youth who drink less than average to catch up to their peers; or a tobacco industry sponsored anti-smoking campaign that encouraged parents to lecture their children on not smoking which triggered more youth to smoke (Healey \& Zimmerman, 2009).

In this paper, we aim to start a wider scientific discussion on intervention backfiring, provide a framework to help frame this discussion, and offer tools that can aid academics in the study of this topic, and support practitioners who need to remain mindful of the potential risks.

\section{Background}

There are numerous systems that provide recommendations on how to design behavior change interventions, including social marketing (Andreasen, 2006; Kotler, Roberto, \& Lee, 2002), evidence-based behavioral medicine (Davidson et al., 2003; Embry \& Biglan, 2008), health behavior change [Oin2013, Prochaska] (Bartholomew, Parcel, Kok, Gottlieb, \& others, 2011), socially influencing systems [Sti2015], persuasive technology [Fog2003], and classic persuasion literature (O'Keefe, 2002).

However, there is no guarantee that intervention designers will achieve positive outcomes, simply by applying scientific models. More often than not, scientific models inspire interventions, rather than dictate how they are implemented (Michie \& Abraham, 2004).

Quite often, interventions that start-out with a solid theoretical underpinning, endup radically different after adapting to real-world necessities, complexities, budget limits, stakeholder feedback, market testing and politics. Within applied contexts, intervention designers commonly blend behavioral science principles with creative processes, leading to the development of innovative interventions that no matter how promising they may appear, always have the potential to exert unforeseen, and possibly negative outcomes. For this reason, it is common to monitor and evaluate new programs.

Scholars or practitioners who report that they have disseminated a backfiring technologies can easily feel embarrassed, or worse, find themselves not just stigmatized, but potentially unfunded or unemployed. Without doubt, there are many practical reasons why people do not formally issue published papers that detail how their digital interventions backfire.

We believe that this stigma has created a climate where the existing body of scientific literature may possess a heavy publication bias, resulting form the overemphasizing of positive outcomes. This has the potential to create a climate where both scien- 
tists and practitioners are at greater risk of disseminating interventions that underperform, and potentially trigger unintended negative outcomes in some populations.

\section{Framework}

In this paper, we construct and present the persuasive backfiring framework, containing two matrices that are used to define categories of backfires and clarify their potential to undermine the efficacy of behavior change interventions.

Fig. 1 presents the intention-outcome matrix, which describes different types of outcomes. The intention-outcome matrix has four axes and four quadrants. To illustrate the matrix, we use an anti binge-drinking program.

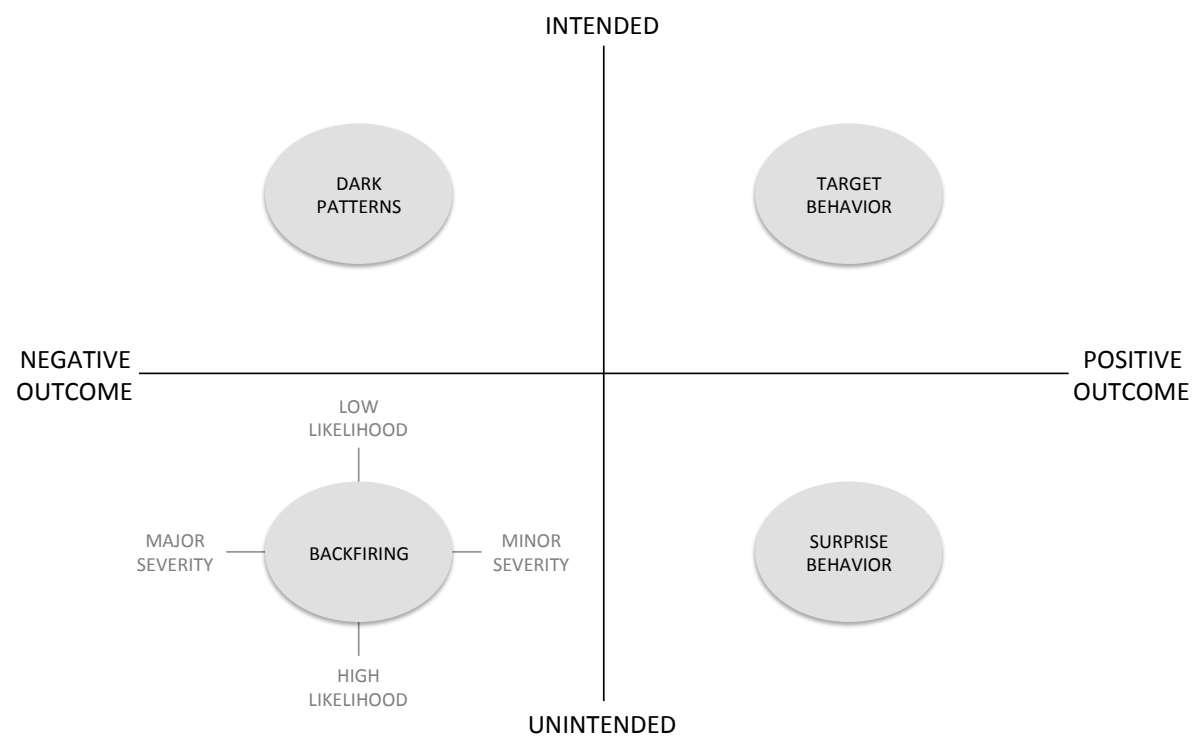

Fig. 1. Intention-Outcome matrix

\subsection{Axes of the Intention-Outcome Matrix}

The intention-outcome matrix uses four axes.

Intended Outcome. An outcome that was intended by the intervention designer. For example, getting university students to reduce their binge-drinking.

Unintended Outcome. Any outcome that the intervention designer did not intended, whether it is a positive or negative outcome. For example, when a binge-drinking screener causes binge drinking among students who use it to compete over who can obtain the highest binge-drinking score.

Positive Outcome. An outcome that serve to the interest of both the intervention designer and the target audience. This is a win-win situation, where both parties bene- 
fit. For example, a binge-drinking screener where the target audience achieves reduced alcohol consumption.

Negative Outcome. An outcome that does not serve to the interest of the target audience. For example, a binge-drinking screener that causes small segments to drink more alcohol.

\subsection{Quadrants of the Intention-Outcome Matrix}

The intention-outcome matrix has four quadrants.

Target Behavior. The primary intended positive behavioral outcome being sought, and typically reported.

Surprise Behavior. A positive behavioral outcome that was not being sought, however was positive and may be reported as an complementary benefit of the intervention.

Backfiring. This category includes a number of negative outcomes, when an intervention causes the opposite of outcome (e.g. more binge drinking instead of less). It also includes "side effects", when the primary behavior is achieved, but it also triggers unintended negative outcomes (e.g. using peer pressure to influence behavior while lowering self-esteem). This quadrant is further subdivided into a matrix that contrasts the likelihood of backfiring (low to high) with the potential severity (minor to major).

Dark Patterns. When an intervention is used for the benefit of the developer, at the loss of the target audience. This is in the realm of unethical applications, including practice such as coercion, deception, and fraud. For instance, some scholars draw attention to dark game design patterns that are used intentionally by a game creator to cause negative experiences for players which are against their best interests and likely to happen without their consent [Lin2015] [Kir2010].

\section{Method}

The taxonomy of backfires was derived through a grounded theory methodology [Cha2014] [Gla2009], based on a corpus of academic, applied, and personal experiences with backfiring behavior change interventions [Bee1990].

We began the process by defining and limiting our selection criteria to interventions that backfire, and cause the opposite behavior, or unanticipated negative consequences that were contrary to the intentions of the program. We excluded interventions that were unsuccessful due to low motivation or high friction, as these constitute ineffective programs, but not backfiring programs. For instance interventions that audiences did not find motivating were omitted, as they did not have enough capacity to move audiences. Similarly, interventions that faced implementation barriers were omitted, as this impacted implementation efficacy or created barriers to usage among target audiences.

To gather qualifying sources, we ran a call for references and examples across several academic, professional, and personal networks. The types of references we col- 
lected included journal papers, articles, program evaluations, and personal experiences. In total, we collected 47 responses.

We systematically reviewed all sources, and only included submissions that qualified as having demonstrated an unintended negative outcome. We also included behavior change interventions that were not implemented within technology per se, but were reasonably implemented in the context of online behavior change campaigns or digital products. We also received submissions of backfiring legislation, which is often used in conjunction with communication campaigns, to elicit social change. In total 30 responses were included in our qualitative analysis.

We carried out a qualitative assessment of the corpus, with a view to developing taxonomy of triggers for backfiring interventions.

\section{$5 \quad$ Findings}

The findings of our study are presented in Fig. 2 as the likelihood-severity matrix, which has four quadrants of backfires distinguished by a: A. low likelihood and minor severity, B. high likelihood and minor severity, C. low likelihood and major severity, and D. high likelihood and major severity. The grey ovals illustrate six clusters, namely inexperience, fineprint fallacy, personality responses, credibility damage, poor judgment, and social psychology.

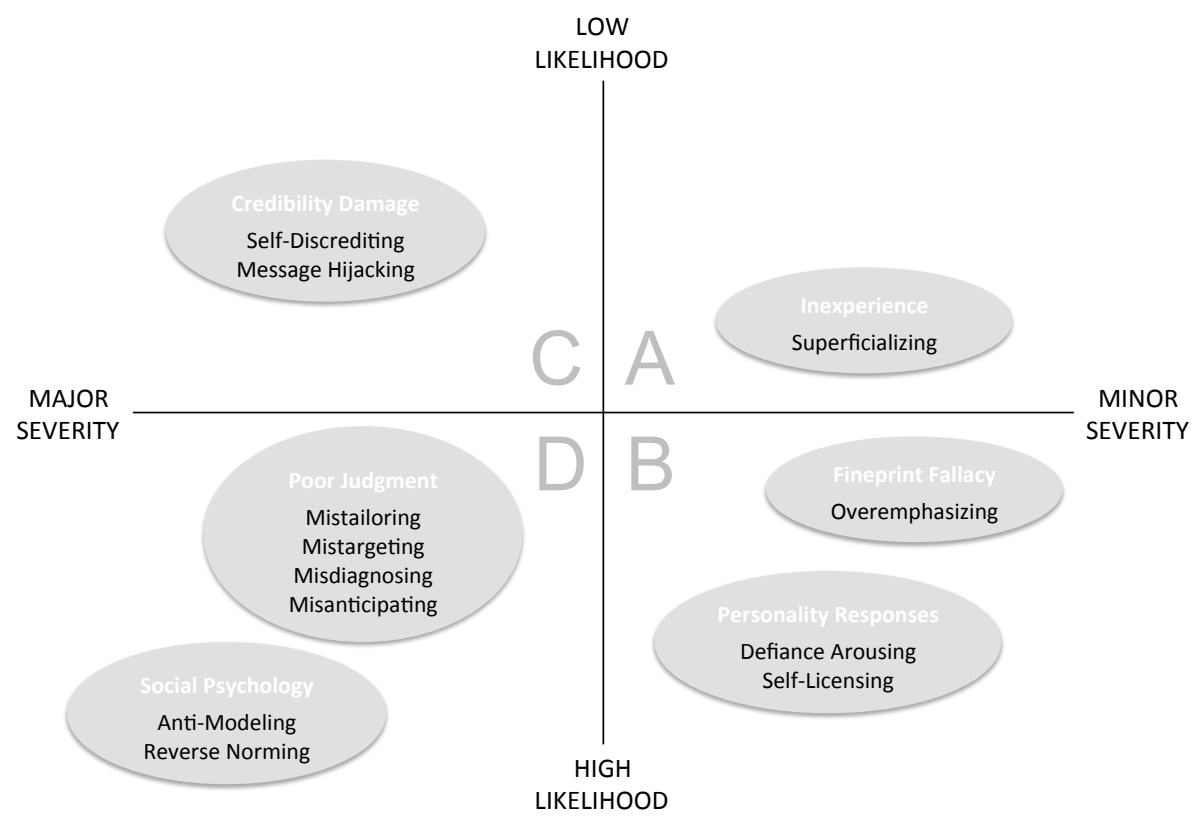

Fig. 2. Likelihood-Severity matrix 
The clusters altogether contain twelve categories comprising taxonomy of persuasive backfiring, which are further discussed in Table 1.

Table 1. Taxonomy of backfires

Description

Examples

\begin{tabular}{ll}
\hline & A: LOW likelihood and MINOR severity \\
& \multicolumn{1}{c}{ Inexperience } \\
\hline $\begin{array}{l}\text { Superficializing } \\
\begin{array}{l}\text { Superficial application } \\
\text { of theory, e.g. copying } \\
\text { tactics without proper } \\
\text { understanding of } \\
\text { underlying strategies } \\
\text { and core principles. }\end{array}\end{array}$ & $\begin{array}{l}\text { There has been research on social media, particularly the } \\
\text { by its gamified aspects competed with the intended target } \\
\text { behavior on information sharing [Kie2011]. More generally, } \\
\text { the research aimed on how gamification elements can } \\
\text { exclusively drive extrinsic motivation, thus ceasing to be } \\
\text { persuasive over the long term, and more problematically, } \\
\text { potentially depleting intrinsic motivation. }\end{array}$ \\
\hline
\end{tabular}

\section{B: HIGH likelihood and MINOR severity}

\section{Overemphasizing \\ Motivate people to take} action for one strongly emphasized benefit, which is accompanied by several hidden harmful factors that are in the fine print.

\section{Fineprint Fallacy}

Stressing "low fat", while still including several unhealthy factors, such as high-sugar.

Or, eco-friendliness of energy sources, e.g. electricity.

Another example, people take one pill a day and their risk of getting HIV is lower. However, if people then practice riskier sex (i.e. without condom), then other STDs may increase.

(http://www.theguardian.com/world/2014/sep/18/truvada-mirclepill-prevent-hiv-controversy).

\section{Personality Responses}

\section{Defiance Arousing}

Resistance to messages that are incompatible with self identity, which may induce undesirable cognitive dissonance and rejection
Guilt and shame messages in anti-drinking ads for drunk drivers are ignored, and in some cases, backfire, when the message is incompatible with how individuals view themselves.

Or, if one is sensitive to authorities, then persuasive messaging involving an authority might provoke rebelling and opposite behavior of the person.

For some, the presence of peer information decreased the savings of nonparticipants who were ineligible for automatic enrollment in a saving plan, and higher observed peer savings rates also decreased savings. Discouragement from upward social comparison seems to drive this reaction [Bes2015]. 


\section{Self-Licensing}

If you have done something good in one area you might feel more freedom of misbehave in other.

For example, earlier research reveals that after donating to charity, people may feel licensed to behave less morally in subsequent decisions [Mar2015]. It demonstrates that donating to charity may have a dark side to it, as it negatively affects subsequent, seemingly unrelated moral behavior, the intention to be environmentally friendly.

\section{C: LOW likelihood and MAJOR severity}

Credibility Damage

\section{Self-Discrediting}

Misalignment of the source and the message credibility.

People have reported less favorable thoughts and attitudes after reading weak arguments presented by a high (vs. low) expertise source.

Similarly, too much fear mongering may discredit a campaign to the point of disbelief or humor. (http://www.talkingdrugs.org/5anti-drugs-campaigns)

\section{Message Hijacking}

Third party actors recontextualize the original messaging with a different meaning, which in most cases undermine the intervention by turning it into a joke.

For instance, creative works designed to cause fear, become a trendy meme with a different meaning, such as humorous cigarette ads of smoking children, reefer madness, fashionable heroin chic, and other trends [Has2007].

Or, an ad campaign on TV for drugs "This is your brain and this is our brain on drugs" failed [Cra2001].

Another backfire is England's Beat Bullying Campaign that gets kids beaten. One reason kids were targeted was because of the scarcity of the bracelets. The campaign was so popular at its launch that supplies of the "Beat Bullying" wristbands quickly sold out.

(http://www.theguardian.com/education/2004/dec/08/schools.uk 2)

\section{D: HIGH likelihood and MAJOR severity}

\section{Poor Judgment}

\section{Mistailoring}

Normative messaging that is displayed also for those who perform better than average.
A drinking screener showed both low and high drinking students how much they consume in comparison to an average consumption. Those that were above the norm felt encouraged coming down, while those below receive an implied message to drink more.

And a boomerang effect [Sch2007], when a descriptive social norm was not accompanied by an injunctive social norm in a 
similar way as described above.

\section{Mistargeting}

When a message that was intended for one audience is misinterpreted by another group of people.
For example, one-size-approach can deter healthy eating behavior change and led to a negative change in attitude towards healthy eating over time.

Playpump is quite a notorious example. It was meant for children to pump water while playing, but ended up with adults using and getting back injuries and other health problems.

(http://www.theguardian.com/commentisfree/2009/nov/24/africa -charity-water-pumps-roundabouts)

\section{Misdiagnosing}

When a behavior change intervention includes processes that are not able to properly diagnose user behavior.
This example is about gaze tracking that was designed to provide proactive help as patients read medical documents. The idea was to use lengthy fixation time as a cue for struggling with the material, and have the system proactively offer help. During the trial, the participants with low health literacy had a slower reading rate, causing the system to inappropriately offer help continually, which just annoyed the users and led to lower comprehension compared to the control condition.

\section{Misanticipating}

Changes in policies or directives that lead to unanticipated usages.
In the Netherlands, the drinking age recently changed from 16 to 18. Consequently, latest news began to draw attention to an observation that the drug use amongst this age group grew tremendously.

Another one, Nebraska's "Give Us Your Troubled Child" law backfires. Technically, under the original version of the Nebraska Safe Haven law, parents could drop off their kids of any age and the state had to take them in, so some parents were bringing in their grownups.

(http://newsblogs.chicagotribune.com/triage/2008/09/fatherleaves-n.html)

Social Psychology

\section{Anti-Modeling}

Frequently expose people to memory triggers of bad behaviors or to temptations in the moment of greatest susceptibility
Being exposed to others experiencing the stress of quitting smoking, for example, triggers the person to want to smoke. Anti-badbehavior interventions can remind people of the bad behavior, thus potentially spark their motivation.

Or, a cookie company had introduced 100-calorie packs of snacks, which instead of eating just one pack led people ate more packs [Lon2009]. (http://portionteller.com/pdf/nytJuly07.pdf) 
Or sometimes, calorie counting can be counterproductive for weight loss.

\section{Reverse Norming}

Interventions that use examples of hugely present bad behaviors hoping that people would start behaving better.

An anti-littering program that used campaign posters contrasted how much littering was happening, which actually conveyed a message that littering is normal, because many people are doing that.

An anti-smoking campaign failed due to relying on the basic message that "teens shouldn't smoke... because they're teens." Exactly what kids like to hear. According to the study, youths in the 10th-12th grade range were 12 percent more likely to smoke for each parent targeted ad they had seen in the last 30 days. According to developmental psychologists, teens 15 to 17 years old tend to reject authoritative messages because they believe they are independent, which renders Philip Morris' ad campaign largely useless. (http://www.naturalnews.com/020996.html)

Two separate studies indicated that D.A.R.E. program was ineffective and actually pushed kids toward drug use and lowered self-esteem. Researchers suspected that the overstated, "peer pressure is around every corner, because everyone is doing drugs but you!" message made some kids actually want to get high as a way of fitting in.

(http://content.time.com/time/education/article/0,8599,99564, 00.html)

\section{Discussion}

We have carried out this research to start a discussion within the scientific community, and to encourage other scholars to extend this line of research. Because of the potential stigma associated with transparent reporting on backfiring interventions, we believe it is not possible to use robust research methods, as it is difficult to collect high quality quantitative studies.

Nevertheless, our study reports an overview of persuasive backfiring, provides a framework for directing further research, and proposes tools to guide academics and support practitioners to be aware of the potential risks in designing persuasive technology.

Based on the present taxonomy, backfires most commonly originate around political tampering (HIPPO), suspected hidden intentions (Phillip Morris), evaluations that do not look at the groups, overdoing a principle therefore provoking mistrust of the message ("your brain on drugs"), and misdiagnosing that leads to the wrong intervention (garbage-in garbage-out). 


\subsection{Scientific Contribution}

The scientific contribution of this paper includes the persuasive backfiring framework, the two matrices (intention-outcome and likelihood-severity), and taxonomy. Interested scholars are encouraged using the framework to define, discuss, and further research behavior change interventions that trigger unintended negative outcomes. Although we have not discussed ethics in this paper, it provides a system to further define ethical and unethical uses of persuasive technology.

The present study identifies a potentially large source of publication bias, as we believe that there is low likelihood that researchers actively submit studies on this subject and journals welcome them for publishing. Finally, this research draws the attention of the Persuasive Technology and behavior change design communities to an important topic, which is routinely overlooked because of stigma and embarrassment. We hope this will enable greater transparency of our fields of study, leading to higher quality persuasive design research and applications.

\subsection{Practitioner Considerations}

Given the ability of technology to employ tailoring techniques, where content can be personalized, the persuasive technology field is better equipped to undertake research on backfiring psychology, and use this knowledge to advise intervention designers when they need to omit influence principles that may be counter-productive to particular segments.

When corporations are obliged, or volunteer to carry out public health interventions to warn the public against their product, these corporations can easily benefit from the intentional use of backfiring interventions. For instance, the "Talk: They'll Listen" campaign is frequently cited as an example of a cleaver antismoking ad campaign that on the outside appeared to be a legitimate antismoking campaign, but which in practice caused an increase in youth smoking (Healey \& Zimmerman, 2009). Consequently, caution should be exercised from policy makers who empower tobacco, alcohol, and pharmaceutical companies to run their own interventions, as these companies can easily design backfire campaigns, that superficially look effective, but at a deeper level, they are actually encouraging the opposite effect.

\section{Conclusions}

The stigma associated with reporting behavior change interventions that trigger negative outcomes, has relegated the topic of intervention backfiring to an informal observation that is widely known, but rarely scrutinized. This has created a climate where scholars routinely overemphasize positive outcomes, while failing to report the fact that the same principle, can also lead to unforeseen negative outcomes.

In this paper, we discussed multiple ways how behavior change interventions can backfire. We provided a framework to help facilitate the discussion of this topic, and created tools to aid academics in the study of this realm, and support practitioners to remain mindful of the potential risks. We encourage researchers to build on this work, 
and take a more systematic look on approaches involving the design of behavior change interventions.

In future, research will need to innovate new ways to study this subject, and extend our scientific and practical knowledge of what pitfalls to avoid when designing technology-supported behavior change interventions. We recommend transparent discussion of backfiring, with an attitude of looking out for them, and then coming up with strategies to reduce them, as early on in the process, or whenever identified.

Acknowledgements. We would like to thank scholars and practitioners who helped us aggregating this highly important scientific knowledge. Especially, we would like to express our gratitude to the Persuasive Technology community members.

\section{References}

1. Andreasen, A. (2006). Social marketing in the 21st century. Thousand Oaks: Sage Publications, Inc.

2. Bartholomew, L. K., Parcel, G. S., Kok, G., Gottlieb, N. H., \& others. (2011). Planning health promotion programs: an intervention mapping approach. John Wiley \& Sons. Retrieved from https://books.google.ca/books?hl=en\&lr=\&id=6u5nyWW5PNUC\&oi=fnd\&pg=PT7\&dq=i ntervention + mapping\&ots=rzFGU9oyhA\&sig=pj5kA18eK7Z99pQL3w8Qw5TxAvc

3. Beer, M., Eisenstat, R. A., \& Spector, B. (1990). Why change programs don't produce change.

4. Beshears, J., Choi, J. J., Laibson, D., Madrian, B. C., \& Milkman, K. L. (2015). The effect of providing peer information on retirement savings decisions. The Journal of Finance, 70(3), 1161-1201.

5. Charmaz, K. (2014). Constructing grounded theory. Sage.

6. Crano, W. D., Burgoon, M., \& Oskamp, S. (Eds.). (2001). Mass media and drug prevention: Classic and contemporary theories and research. Psychology Press.

7. Cugelman, B., Thelwall, M., \& Dawes, P. (2011). Online Interventions for Social Marketing Health Behavior Change Campaigns: A Meta-Analysis of Psychological Architectures and Adherence Factors. Journal of Medical Internet Research, 13(1), e17. http://doi.org/10.2196/jmir.1367

8. Cunningham, J. A., Wild, T. C., Cordingley, J., Van Mierlo, T., \& Humphreys, K. (2009). A randomized controlled trial of an internet-based intervention for alcohol abusers. Addiction, 104(12), 2023-2032.

9. Davidson, K., Goldstein, M., Kaplan, R., Kaufmann, P., Knatterud, G., Orleans, C., ... Whitlock, E. (2003). Evidence-Based Behavioral Medicine: What Is It and How Do We Achieve It? Annals of Behavioral Medicine, 26(3), 161-171.

10. Embry, D., \& Biglan, A. (2008). Evidence-based Kernels: Fundamental Units of Behavioral Influence. Clinical Child and Family Psychology Review, 11(3), 75.

11. Farvolden, P., Denisoff, E., Selby, P., Bagby, R. M., \& Rudy, L. (2005). Usage and longitudinal effectiveness of a Web-based self-help cognitive behavioral therapy program for panic disorder. Journal of Medical Internet Research, 7(1). Retrieved from http://www.ncbi.nlm.nih.gov/pmc/articles/PMC1550639/

12. Fogg, B.J.: Persuasive Technology: Using Computers to Change What We Think and Do. San Francisco: Morgan Kaufmann (2003) 
13. Glaser, B. G., \& Strauss, A. L. (2009). The discovery of grounded theory: Strategies for qualitative research. Transaction Publishers.

14. Hastings, G. (2007). Social marketing: why should the devil have all the best tunes?. Butterworth-Heinemann.

15. Healey, B., \& Zimmerman, R. S. (2009). The new world of health promotion: New program development, implementation, and evaluation. Jones \& Bartlett Learning. Retrieved from

https://books.google.ca/books?hl=en\&lr=\&id=KXdgKKMI8dsC\&oi=fnd\&pg=PR15\&dq= The+New+World + of + Health+Promotion:+New+Program+Development,+Implementation \&ots $=$ SJs2PAGXc-\&sig=uDPRaKsia wnCNT5trH bUWKWt8

16. Kietzmann, J. H., Hermkens, K., McCarthy, I. P., \& Silvestre, B. S. (2011). Social media? Get serious! Understanding the functional building blocks of social media. Business horizons, 54(3), 241-251

17. Kirkland, A., \& Metzl, J. M. (Eds.). (2010). Against health: How health became the new morality. NYU Press.

18. Kotler, P., Roberto, N., \& Lee, N. (2002). Social marketing: improving the quality of life (2nd ed.). California: Sage Publications, Inc.

19. Lenert, L., Munoz, R., Perez, J., \& Bansod, A. (2004). Automated e-mail messaging as a tool for improving quit rates in an internet smoking cessation intervention. Journal of the American Medical Informatics Association, 11(4), 235-240.

20. Linehan, C., Harrer, S., Kirman, B., Lawson, S., \& Carter, M. (2015, April). Games against health: a player-centered design philosophy. In Proceedings of the 33rd Annual ACM Conference Extended Abstracts on Human Factors in Computing Systems (pp. 589600). ACM.

21. London, L. (2009). Guiltless Girls: Unpacking 100-calorie Snacks.

22. Meijers, M. H., Verlegh, P. W., Noordewier, M. K., \& Smit, E. G. (2015). The dark side of donating: how donating may license environmentally unfriendly behavior. Social Influence, 1-14.

23. Marshall, A., Leslie, E., Bauman, A., Marcus, B., \& Owen, N. (2003). Print versus website physical activity programs A randomized trial. American Journal of Preventive Medicine, 25(2), 88-94.

24. Michie, S., \& Abraham, C. (2004). Interventions to change health behaviours: evidencebased or evidence-inspired? Psychology \& Health, 19(1), 29-49.

25. Oinas-Kukkonen, H. (2013). A foundation for the study of behavior change support systems. Personal and ubiquitous computing, 17(6), 1223-1235.

26. O'Keefe, D. (2002). Persuasion: Theory and Research. London: Sage Publications, Inc.

27. Prochaska, J. O., \& Velicer, W. F. (1997). The transtheoretical model of health behavior change. American journal of health promotion, 12(1), 38-48.

28. Schultz, P. W., Nolan, J. M., Cialdini, R. B., Goldstein, N. J., \& Griskevicius, V. (2007). The constructive, destructive, and reconstructive power of social norms.Psychological science, 18(5), 429-434.

29. Stibe, A.: Towards a Framework for Socially Influencing Systems: Meta-Analysis of Four PLS-SEM Based Studies. In: MacTavish, T., Basapur, S., (eds.) Persuasive Technology. 10th International Conference, PERSUASIVE 2015, Chicago, IL (USA), June 4-5, 2015. Proceedings. Lecture Notes in Computer Science. London: Springer (2015)

30. Webb, T., Joseph, J., Yardley, L., \& Michie, S. (2010). Using the Internet to Promote Health Behavior Change: A Systematic Review and Meta-analysis of the Impact of Theoretical Basis, Use of Behavior Change Techniques, and Mode of Delivery on Efficacy. Journal of Medical Internet Research, 12(1), e4. http://doi.org/10.2196/jmir.1376 